\title{
Investigation of Additively Manufactured PEEK \\ Modified With Glass Microballons as a Function of Density and Volume Fraction
}

Sagar Mahalingappa Baligidad ( $\sim$ smbaligidad@gmail.com )

CMR Institute of Technology https://orcid.org/0000-0003-2602-736X

Chethan Kumar Gangadhara

CMR Institute of Technology

Maharudresh Aralikatte Chandrashekhar

CMR Institute of Technology

\section{Research Article}

Keywords: 3D Printing, Syntactic foam, PEEK, hallow glass microballons, Air voids, etc

Posted Date: December 17th, 2021

DOl: https://doi.org/10.21203/rs.3.rs-1022471/v1

License: (c) (1) This work is licensed under a Creative Commons Attribution 4.0 International License.

Read Full License 


\section{Abstract}

Low density and strong mechanical characteristics make hollow glass microballons (HGM) filled polyehteretherketone (PEEK) composites excellent for aerospace, transportation and civil applications. In this study, PEEK was filled with different densities of HGMs (low, medium, and high) and varied volume fractions $\left(V_{f}\right)$ of HGMs $(10 \%, 15 \%$, and $20 \%)$ and exposed to different strain rates to investigate thermal, physical, energy absorption, and other physico-mechanical responses. PEEK/HGMs composites demonstrated a substantial strain rate impact, with the strain rate sensitivity factor increasing as the strain rate increased while decreasing as the filler $V_{f}$ increased. The density of the composites was also shown to be inversely related to their strength properties. Incorporating high-density HGMs into the PEEK resulted in the lowest composite density so far reported while ensuring mechanical properties. Scanning electron microscopy images revealed that the HGM dispersion is uniform inside the matrix. Thermal stability of the syntactic foam was investigated by using Thermo Gravity Analysis (TGA) under inert atmosphere and oxidative environment conditions. The infusion of microspheres enhances the thermal stability of LDPEs, MDPEs, and HDPEs samples in an inert environment, with HDPEs samples being the most thermally stable. This might lead to the formation of a strong bond between polymer chains and HGM particles.

\section{Introduction}

To produce low density syntactic structures, hollow microspheres are spread in a matrix material (matrix materials may be polymer, ceramic, or metal). HGM filled syntactic foams have been proposed as buoyancy-aid materials for application in the marine [1], aerospace [2], and petrochemical industries [3]. The most essential property of syntactic foams is their flexibility. To create syntactic foams with desired qualities, the structure and function of microspheres, as well as the matrix composition, are changed. It has attracted a lot of attention because of its high specific strength, excellent thermal expansion, thermal stability, and high durability, all of which are desirable composite property [4]. In fact, producing low density syntactic foams with high mechanical qualities is challenging. Moldability, recycling, and mechanical quality are all advantages of thermoplastic syntactic foams over thermoset syntactic foams. The methods like vacuum moulding [5], injection moulding [6], and Extrusion [7] have been employed to fabricate thermoplastic syntactic foams. The presence of GM in the matrix has the effect of preventing fracture spread during loading. As a result, the mechanical characteristics of the polymer matrix have improved [8]. Defects will occur if the distribution of microspheres inside the matrix is uneven [9]. Syntactic foam failure mechanisms include fracture bending, fracture deformation, and spalling [10]. Syntactic foams are dominated by bending, which causes the edges of the cells to bend when force is applied, making the matrix weaker and more compliant [11]. To achieve dynamic response, a SHP Bar method was used to employ high strain rate loading to porous materials [12]. Several studies have been published that show how different approaches may be used to create foams with enhanced mechanical characteristics and lower density. J-Z Liang developed ABS syntactic foam. The ABS syntactic foam's tensile and flexural characteristics were enhanced due to the strong interfacial bonding between the ABS 
and microballons [13]. Patankar S $\mathrm{N}$ et al, developed HDPE/HGM composite matrix with improved tensile strength and reduced density, and thermal conductivity. However, the poor toughness of these composites necessitated the use of a compatibilizer, which resulted in better toughness levels [14]. Doumbia et al.'s developed high impact polypropylene composite by using six different types of microspheres [15], where four different types of microspheres fragmented during the melt operation, resulting in a denser polymer compared to neat polymer. HGMs with a higher thickness to diameter ratio were much more robust in the melt operation. Swetha et al. developed an epoxy matrix with three distinct HGM densities. The density of the matrix decreased linearly as the $\mathrm{V}_{\mathrm{f}}$ of HGM increased. Furthermore, epoxy matrix doped with $30 \mathrm{vol} \%$ HGM showed improved mechanical properties [16]. Li et al. [17] studied the mechanical behaviour of syntactic foam at various strain rates. Compressive characteristics have been found to be strain rate dependent. Zhang et al. [10] recorded, the compressive strength of a polymer matrix supplemented with carbon microsphere reduced as the filler quantity increased. Meanwhile, improved interfacial adhesion may result in improved fracture toughness. There are few researches that concentrate on tensile properties of HGM loaded polymers. Gupta et al. [18] treated tensile testing of sixteen distinct syntactic foams using four different HGMs. They discovered that when the volume percent of HGM increases, both tensile strength and modulus drop. When the volume percentage of HGM in a polymer is large, the polymer's absolute strength tends to be low. On the other hand, the mechanical characteristics and fracture processes of HGM filled polymers with a lower HGM volume percent have not been thoroughly studied.

Modifying the surface structure of HGMs is another technique to improve the mechanical characteristics of syntactic foam. The compatibility between the components might be improved by modifying the surface structure of HGMs. Bharath Kumar et al. created an HDPE/HGM composite matrix using a silane coupling agent on the HGM surface. They noticed that the composites had enhanced strength as a result of the strong interfacial bonding that had established between the HDPE and the HGM [19]. Many of these scenarios benefit from additive manufacturing (AM) methods, particularly when low hollow particle volume percent syntactic foams with complex-design parts are required [20]. According to the new study, additive printing technology may now be used to create composites like carbon and glass microsphere syntactic foams [21, 22]. PEEK has shown to be an excellent lubricant when used for seawater lubrication and saltwater corrosion resistance [23]. These inhomogeneities have a substantial impact on the characteristics of such particles and the composites that arise.

Given the gaps in the literature, which mostly focused on material types and matrix media as the most important elements in the production of syntactic foams. However, there were limited literature studies on the influence of SF manufacturing processes. The characteristics of the composite are more directly connected to the features of integral materials and their volume fractions in this work, which employs borosilicate glass microballoons to produce syntactic foams. The current study investigates how the filament extrusion process affects the unique features of PEEK syntactic foams under diverse matrix compositions. PEEK filament with different volume fractions of glass microspheres $(10 \%, 15 \%$, and $20 \%)$ was synthesised by extrusion technique, and tensile test specimens for mechanical testing were 3D 
printed with a commercial printer. Under low strain rate loadings as well as dynamic compressions, all tensile tests have been extensively assessed. Correlations between material characteristics, microstructural parameters, and the influence of $V_{f}$ and wall thickness on HGMs have also been investigated.

\section{Experimental Method \\ 2.1. Materials}

For this investigation, PEEK granules of grade PE10 with a melt flow of $24 \mathrm{~g} / 10$ min and a molecular weight of $98,200 \mathrm{~g} / \mathrm{mol}$ were used, as well as hallow glass microballons (HGM) of grade SID350 from sigma Aldrich. Table 1 lists the characteristics of HGMs. To surface treat the PEEK, sulfuric acid with a concentration of $95-98 \%$ and a molecular weight of $98.079 \mathrm{~g} / \mathrm{mol}$, as well as ethanol and $\mathrm{NaOH}$ were procured from Sigma Aldrich.

\subsection{Processing}

The PEEK pellets were submerged in concentrated $\mathrm{H}_{2} \mathrm{SO}_{4}$ for a regulated period of time before being immersed in water for $20 \mathrm{sec}$ to eliminate any leftover $\mathrm{H}_{2} \mathrm{SO}_{4}$. The surface treated PEEK pellets and HGM particles were thoroughly mixed by using the Bra bender, which were then fed into the single screw extruder hopper. To produce a $1.75 \mathrm{~mm}$ diameter filament, an extruder temperature profile of $300^{\circ}, 350^{\circ}$, $350^{\circ}$, and $380^{\circ} \mathrm{C}$ was maintained from hopper to die, with a screw speed of $18 \mathrm{rpm}$. During extrusion, the screw speed and mix temperature settings were chosen to preserve and ensnare the air holes in the filament. PEEK and HGM composite filaments were produced with varying volume fractions of HGMs for different densities of $\mathrm{HGMs}$, such as $10 \%, 15 \%$, and $20 \%$. Using newly produced PEEK/HGMs filaments, the test specimens were printed on an Ultimaker IMKI 3D printer. Because of the presence of HGMs in the PEEK matrix, the 3D printer used a $0.6 \mathrm{~mm}$ diameter hot end nozzle to avoid printing blockage. To ensure no porosity between the layers, all parts were printed at $100 \%$ density, $0.2 \mathrm{~mm}$ layer thickness, and a print speed of $50 \mathrm{~mm} / \mathrm{sec}$, with the exception of porosity inside the filament.

\subsection{Density measurement}

The tensile test specimen is used to calculate the densities of the syntactic foam matrix and it is computed using ASTM D792-13. The sample's weight was divided by its volume, and the average of five values was used in the computation. The theoretical densities were derived by Eq. (1):

$\rho_{\text {theor }}=\rho_{H G M} \cdot W_{f}+\rho_{P} \cdot\left(1-W_{f}\right)(1)$

where $\rho_{\text {theor }}$ is the theoretical density of the matrix. $\rho_{\mathrm{HGM}}$, and $\rho_{\mathrm{P}}$ are the densities of the HGM and PEEK respectively and $\mathrm{W}_{\mathrm{f}}$ - weight fraction of HGM.

\subsection{Mechanical properties}


Tensile tests of PEEK/HGM composites were performed in accordance with ASTM 638 V 5 using a VectorPro MT universal tester. Fig. 1 shows the $1 \mathrm{x}$ macroscope image of 3D printed tensile test samples of different PEEK/HGM composites. These stroke rates result in nominal strain rates of $10^{-1}, 10^{-2}, 10^{-3}$, and $10^{-4} \mathrm{~s}^{-1}$, which were calculated by dividing the cross-head stroke rate of the machine by the specimen gauge length. In the next part, various outcomes from the experiments are provided.

\subsection{Thermal analysis}

Universal TGA 2950 TA instrument was used to inspect the thermal degradation characteristics of PEEK/HGMs composites under an inert atmosphere. During the process, all samples were heated at a constant rate of $10^{\circ} \mathrm{C}$ from $350^{\circ} \mathrm{C}$ to $900^{\circ} \mathrm{C}$. The composites were also thermally analysed in the air using a TA Instruments Q500 TGA. The thermogram curve was plotted by residual weight\% vs temperature to examine the degradation temperatures at the maximum weight loss. Differential scanning calorimetry (DSC) of 3 STARe System was used to derive the Tg of the composites.

\subsection{Morphology study}

Scanning Electron Microscopy (SEM) investigations were carried out using a Carl Zeiss AxioVertA1 LowVacuum SEM in order to evaluate microstructure of the fractured surfaces. All of the broken tensile test parts were coated with conductive material before to SEM evaluation, and the analysis was performed at a $20-\mathrm{kW}$ acceleration voltage.

\subsection{Numerical study}

The modulus of composite was simulated using ABAQUS/Standard. The unit cell method was used to make the simulation process easier. A cubical unit structure was chosen to match the inclusive structure. On the unit cell's border, periodic boundary conditions were applied. In ABAQUS, displacement equations can be applied [24]. The original face's nodes and the image face's nodes were assured to be in the same relative location. FEM software was used to develop uniform cubical mesh with the sphere at center, as shown in Fig. 2 (a). On the unit cell, a consistent 1MPa tensile stress was applied and the relative stress distribution is shown in Fig. 2 (b). According to the data, tension distributed perpendicularly to the loading direction around the circle is much more than stress distributed in other places. For simulation, different densities of HGMs were selected. Table 3 contains the diameter and wall thickness of all HGMs, which were utilised in the computation.

\section{Results And Discussion}

\subsection{MFI and Rheology of PEEK/HGM}

The flowability of PEEK and its composite is determined using melt flow index (MFI), which was measured at $400^{\circ} \mathrm{C}$, in context of filament manufacture by extrusion and subsequent 3D printing of parts. It is observed from Table 2, MFI decreases as HGM concentration rises due to filler resistance to polymer flow [25]. When compared to its composites, PEEK had the highest MFI (5.20 $\pm 4 \mathrm{~g} / 10 \mathrm{~min})$, and MFI drops 
as HGM density increases, which might pose printing concerns. When compared to other concentrations, the PEKK with $20 \%$ of different densities of HGM demonstrated the greatest decline in MFI.

LDPE composites with higher HGM content showed reduced MFI, as seen in Fig. 3 (a). MFI was decreased by $34.6 \%, 48.1 \%$, and $63.5 \%$ at $10 \%, 15 \%$, and $20 \%$, respectively, when compared to neat PEEK [26]. MFI was also lowered in MDPE composites when HGM concentrations were raised, as seen in Fig. 3. (b). MFI was decreased by $40.4 \%, 59.5 \%$, and $69.3 \%$ at $10 \%, 15 \%$, and $20 \%$, respectively, when compared to PEEK. Similarly, greater HGM concentrations resulted in lower MFI in HDPE composites, as seen in Fig. 3. (c). When compared to PEEK, MFI reduced by $44.2 \%, 63.5 \%$, and $76.9 \%$ at 10,15 , and $20 \%$, respectively. Reduced MFI must be studied carefully and accounted for by raising the printing temperature, particularly for composite with a higher $\mathrm{HGM} \%$. To reduce warpage, the bed temperature is maintained constant, and the multiplier factor was modified to account for the greater $\mathrm{HGM} \%$. The MFI of polymer rises as the filler infusion increases, as seen throughout the frequency sweep [27]. PEEK has a shear-thinning area at higher frequencies. The limitation of polymer chain motions by HGMs causes LDPE (10\%, $15 \%$, and $20 \%)$, $\operatorname{MDPE}(10 \%, 15 \%$, and $20 \%)$ and $\operatorname{HDPE}(10 \%, 15 \%$, and $20 \%)$ to behave similarly, with a little increase in $\eta$ '. $\mathrm{H} 60$ has the highest $\eta$ ' among the composites.

\subsection{Density and Microstructure}

The existence of substrate porosity may be evaluated via density measurements. The measured and theoretical densities of PEEK and PEEK/HGMs composites are shown in Table 3. The law of mixtures was used to compute the theoretical density values for PEEK composites. PEEK/HGMs composites revealed decreased densities as HGM concentrations raised from 10-20\% except for the measured density of LDPE composites. The LDPE20 composite had the highest density with the lowest strength. Due to high shear stress, deformation of the HGM particle occurs during extrusion and 3D printing operations, resulting in increase of a composite density higher than that of neat PEEK. PEEK composites having varied quantities of MD-HGMs had a density equivalent to neat PEEK. Because of HGM partial deformation during processing, their measured densities are greater than the theoretical ones. The measured densities of the PEEK composite containing various concentrations of HD-HGMs, were nearly similar to the theoretical value, with just a little variation that could be attributed to two reasons. One reason might be the HGM's mechanical robustness, which enables them to endure high shear melt processing. This is further supported by the SEM results of these composites, which show spherical HGMs embedded in the polymer matrix. A high-magnification SEM picture of a typical HDPE10 crosssection is shown in Fig. 4(a). The dispersed HGMs and gap between the layers reveal the microstructure. A similar microstructure can be found for HDPE15 and HDPE20 sections in Fig. 4(b\&c). The core of the filament seems to have more porosity than the rim surface, which is due to the uniform flow of polymer matrix along the barrel surface, which creates a closed film on the filament by trapping the porosity within. In Fig. 4(b\&c), it can be shown that HGMs and the PEEK matrix have a high compatibility, which improves the mechanical strength of the material when compared to clean PEEK. Another factor might be the existence of air-voids between the layers, which had the effect on the density of the composite. 
Among the HGMs composite, the HDPE20 demonstrated the greatest reduction in density and had the highest crush strength when compared to the neat PEEK.

\subsection{Tensile testing}

Figure 5 depicts the load vs displacement graph of neat PEEK material evaluated at $5 \mathrm{~mm} / \mathrm{min}$ loading rate. The stiffness of the curve was calculated by fitting the first linear segment with a linear curve. Fig. 6(a) shows the tensile strength of PEEK/HGMs composites containing different density of HGM at four different strain rates. The tensile strength is shown to be strain rate sensitive. It exhibits increased strength as the strain rate increases, which is consistent with the findings of Mae et al. research's [28]. The rate sensitivity of PEEK/HGM composites has been shown to be influenced by its viscoelastic behaviour, which tends to reduce absolute strength due to microscopic local damage. However, the inclusion of HGM, may have little influence on the overall sensitivity of PEEK/HGMs composites [29]. Meanwhile, the tensile strength of PEEK decline as $V_{f}$ rises for LDPE and MDPE as compared to neat PEEK, indicating that the addition of glass microspheres significantly reduces the tensile strength of the material. But the tensile strength of PEEK increase as $\mathrm{V}_{\mathrm{f}}$ rises for HDPE.

\subsection{Strain rate sensitivity}

The corresponding tensile modulus was measured using an extensometer. Despite the fact that the strain rates are all low, the tensile moduli of most specimens with the same $V_{f}$ rise as the strain rates increase, as seen in Fig. 6(b). This pattern is similar to tensile strength. Tensile moduli, on the other hand, increase in step with $V_{f}$. Tensile moduli, unlike tensile strengths, do not appear to be reduced. It shows that introducing glass microspheres reduces tensile modulus considerably, and that tensile modulus somehow doesn't change as much as tensile strength when $V_{f}$ rises. It must be mentioned that, for LDPEs and MDPEs composites, the increase in specimen density is proportional to the rise in $V_{f}$. However, when the $V_{f}$ for HDPEs increases, the specimen density decreases. As a consequence, Fig. 6(c), depicts the particular moduli of specimens. Except for a minor disruption at $20 \% V_{f}$, all glass microsphere specimens show a modest increase in tensile modulus. At high strain rates, the infusion of HD-HGM will raise the specific tensile modulus by a small amount. This is because the HD-HGM has the potential to reduce a material's density more than its tensile modulus.

\subsection{Simulation of tensile modulus}

Using a unit cell method, the tensile modulus was simulated in quasi-static conditions. Both LDPEs and MDPEs samples show a decreasing trend with increasing $V_{f}$, will weaken the strength of both composites. As seen in Fig. 7, HDPEs samples have a constant modulus as $\mathrm{V}_{\mathrm{f}}$ increases. Even if the glass microsphere is made substantially stronger by increasing the wall thickness, the modulus will remain constant as $\mathrm{V}_{\mathrm{f}}$ increases. The simulation results of HDPEs samples match well to the experiment results. The experiment findings are often a bit smaller than the LDPEs and MDPEs samples simulation results, due to the ideal bonding situation in simulation, as well as no voids, early matrix crack, and glass microsphere crush. 


\subsection{Thermal analysis}

The thermal properties of PEEK loaded with varied densities of HGMs with variable concentrations were evaluated using the TGA method. In an inert environment, samples of PEEK, LGPEs, MDPEs, and HDPEs were analysed, and the average results of the triplicate analyses are shown in Fig. 8(a), demonstrating that adding HGMs to PEEK caused a considerable change in PEEK's thermal degrading behaviour. It was found that PEEK and its composites decompose in two stages, with PEEK decomposes at a temperature of roughly $550^{\circ} \mathrm{C}$, which is substantially higher than the temperature at which most polymers decompose. In first stage, decomposition occurs around $580^{\circ} \mathrm{C}$ and is related to arbitrary chain scission of the ether and ketone bonds [30]. After $600^{\circ} \mathrm{C}$, the second stage of breakdown starts, which is attributed to the development of residue as a result of crosslink breaking and dehydrogenation, resulting in a thermally stable carbonaceous char. Within $30^{\circ} \mathrm{C}$ of time, PEEK loses $30 \%$ of its weight in the initial stage, and continues to drop $10 \%$ of its weight between 580 and $600^{\circ} \mathrm{C}$. As a result, the first stage resulted in a total weight decrease of $40 \%$. There is no foreign substance in the PEEKs media that is associated with a $40 \%$ weight reduction. In the second step, just $10 \%$ of the weight is lost up to $800^{\circ} \mathrm{C}$, resulting in a $50 \%$ yield. Beyond $800^{\circ} \mathrm{C}$, there is minimal further loss, and the material appears to be stable at $850^{\circ} \mathrm{C}$. A $40 \%$ weight loss shows that formation of aromatic molecules as products, presumably in the form of phenol, a significant PEEK breakdown product [31].

HDPEs samples had a slightly higher beginning temperature than LDPEs and MDPEs samples for the HGM filled PEEK; nonetheless, all three composites have a higher beginning temperature than PEEK. The initial stage of decomposition of LDPEs and MDPEs samples is comparable, with weight loss of roughly $28 \%$ and $27 \%$, respectively. At $580^{\circ} \mathrm{C}$, the decomposition process begins, and both materials progress to the second stage of decomposition. Further, after $750^{\circ} \mathrm{C}$, small loses in weight occurs and the final remaining weight of the materials for LDPEs and MDPEs samples is $65 \%$ and $68 \%$ respectively. For HDPEs samples, the initial decomposition begins at $600^{\circ} \mathrm{C}$, with the weight loss of $21 \%$ and continuing to decom pose at a faster rate than LDPEs and MDPEs samples. After $800^{\circ} \mathrm{C}$, the weight of the HDPEs samples decreased significantly, and the final residual weight of the HDPEs was $71 \%$, slightly higher than the total of the mass fractions of the PEEK, LDPEs, and MDPEs samples, as well as the char fraction.

Similarly, the thermal properties of PEEK loaded with varied densities of HGMs with variable concentrations were evaluated in an oxidative environment as shown in Fig. 8(b). Thermal oxidative degradation begins between $510^{\circ} \mathrm{C}$ and $530^{\circ} \mathrm{C}$ for PEEK, LDPEs, and MDPEs samples. The temperature at which thermal oxidative decomposition begins in HDPEs samples is somewhat greater, at around $560^{\circ} \mathrm{C}$. PEEK loses $35 \%$ of its weight in the first stage, with $30 \%$ of the weight loss occurring within a $30^{\circ} \mathrm{C}$ time frame, which correlates to thermal disintegration under inert atmosphere, suggesting that scission of ether and ketone bonds does not enhance by an oxidative environment. The rest of the PEEK weight is lost during the second stage, which involves thermally oxidising the whole material at $720^{\circ} \mathrm{C}$. LDPEs and MDPEs samples lose weight at a slower pace than PEEK, although having a same commencement of thermal oxidative decomposition temperature. The first decomposition stage is responsible for a $3 \%$ weight loss difference between LDPEs and MDPEs samples at roughly $580^{\circ} \mathrm{C}$, with weight losses of $25 \%$ 
and $22 \%$, respectively. In the second stage, LDPEs and MDPEs samples continue to lose $35 \%$ and $32 \%$ weight, respectively, at a comparable pace as PEEK and there is no further decomposition of materials. For HDPEs samples, the initial decomposition begins at $600^{\circ} \mathrm{C}$, with the weight loss of $20 \%$ and continuing to decompose at a faster rate than LDPEs and MDPEs samples. After $700^{\circ} \mathrm{C}$ there in no further decomposition. The addition of microspheres enhances the thermal stability of LDPEs, MDPEs, and HDPEs samples in an inert environment, with HDPEs samples being the most thermally stable.

The glass transition $(\mathrm{Tg})$ temperatures from DSC analysis of PEEK and PEEK/HGMs samples are shown in Table 3. The DSC analysis reveals that the Tg of the neat PEEK, LDPEs and MDPEs samples are not considerably different. When the Tg values of HDPEs samples and plain PEEK are compared, the $\mathrm{Tg}$ values of HDPEs samples are greater. This reveals that while HD-HGMs increase the physical interactions between the microspheres and PEEK, improving the mechanical characteristics of the syntactic foams, they have no effect on the composite's Tg.

\section{Conclusion}

In this work, extrusion process was used to make PEEK composites with three different densities of HGMs and varying volume fractions ranging from $10-20 \%$, and test samples were created using 3D printing technology for usage in weight-sensitive contexts. Filament and 3D printed components are mechanically characterised to assess their flexibility and practicality for 3D applications. The PEEK filled with high density HGMs showed good intact within the PEEK matrix, because they endure the melt processing better than other two (LD and MD) HGMs. Increased HGM density resulted in lower PEEK composite density and better mechanical characteristics, even at low strain rates. MFI decreases as HGM density rises, which might cause printing issues. The PEKK with $20 \%$ of varied densities of HGMs showed the largest decline in MFI when compared to other concentrations. The increased compatibility between PEEK and HD-HGM particles was demonstrated by SEM images. The addition of high density HGMs to PEEK improves the thermal stability of the composite. HDPE is extremely heat resistant, with decomposition below $550{ }^{\circ} \mathrm{C}$.

\section{Declarations}

Funding - Not applicable

Conflicts of interest - The authors declare that they have no competing interests

Data transparency - Not applicable

Code availability - Not applicable

Ethics approval - Not applicable

Consent to participate - Not applicable 


\section{Consent for publication- Not applicable}

\section{Authors' contributions}

Conceptualization: [SAGAR BALIGIDAD];

Methodology: [SAGAR BALIGIDAD], [CHETHAN KUMAR G];

Formal analysis and investigation: [MAHARUDRESH A C], [CHETHAN KUMAR G];

Writing - original draft preparation: [SAGAR BALIGIDAD], [MAHARUDRESH A C];

Writing - review and editing: [SAGAR BALIGIDAD], [MAHARUDRESH A C];

Resources: [SAGAR BALIGIDAD], [CHETHAN KUMAR G];

Supervision: [SAGAR BALIGIDAD];

\section{References}

1. Tagliavia G, Porfiri M, Gupta N. Analysis of flexural properties of hollow-particle filled composites. Compos Part BEng. 2010;41(1):86-93.

2. Wang LJ, Yang X, Zhang J, Zhang C, He L. The compressive properties of expandable microspheres/epoxy foams. Compos Part B-Eng. 2014;56:724-32.

3. Huang RX, Li PF. Elastic behaviour and failure mechanism in epoxy syntactic foams: The effect of glass microballoon volume fractions. Compos Part B-Eng. 2015;78:401-8.

4. L. Jayavardhan, B.R. BharatKumar, M. Doddamani, A.K. Singh, S. Zeltmann, and N. Gupta, Compos. Part B Eng. 130, 119 (2017).

5. R. Bharath Kumar, M. Doddamani, S.E. Zeltmann, N. Gupta, M.R. Ramesh, and S. Ramakrishna, Mater. Des. 92, 414 (2016).

6. Lawrence, Else; Pyrz, Ryszard (2001). Viscoelastic Properties of Polyethylene Syntactic foam with Polymer Microballoons. Polymers and Polymer Composites, 9(4), 227237. doi:10.1177/096739110100900401

7. Zhang LY, Ma J. Effect of coupling agent on mechanical properties of hollow carbon microsphere/phenolic resin syntactic foam. Compos Sci Technol. 2010;70(8):1265-71.

8. Gupta N, Ye R, Porfiri M. Comparison of tensile and compressive characteristics of vinyl ester/glass microballoon syntactic foams. Compos Part B-Eng. 2010;41(3):236-45.

9. d'Almeida JRM. Evaluation of the compressive yield strength of hollow glass microsphere - epoxy composites as a function of the microsphere/epoxy interface strength. Polym Polym Compos. 2007;15(6):445-51. 
10. Zhang LY, Ma J. Effect of coupling agent on mechanical properties of hollow carbon microsphere/phenolic resin syntactic foam. Compos Sci Technol. 2010;70(8):1265-71.

11. Swetha C, Kumar R. Quasi-static uni-axial compression behaviour of hollow glass microspheres/epoxy based syntactic foams. Mater Design. 2011;32(8-9):4152-63.

12. Wang PF, Xu SL, Li ZB, Yang JL, Zhang C, Zheng H, et al. Experimental investigation on the strain-rate effect and inertia effect of closed-cell aluminum foam subjected to dynamic loading. Mat Sci Eng aStruct. 2015;620:253-61.

13. Liang J-Z. Mechanical properties of hollow glass bead-filled ABS composites. J Thermoplast Compos Mater 2005; 18:407-16.

14. Patankar SN, Kranov Y. Hollow glass microsphere HDPE composites for low energy sustainability. Mater Sci Eng A 2010; 527:1361-6.

15. Doumbia AS, Bourmaud A, Jouannet D, Falher T, Orange F, Retoux R, et al. Hollow microspheres poly-(propylene) blends: Relationship between microspheres degradation and composite properties. Polym Degrad Stab 2015;114:146-53.

16. Swetha C, Kumar R. Quasi-static uni-axial compression behaviour of hollow glass microspheres/epoxy based syntactic foams. Mater Des 2011;32:4152-63.

17. Li P, Petrinic N, Siviour CR, Froud R, Reed JM. Strain rate dependent compressive properties of glass microballoon epoxy syntactic foams. Mat Sci Eng a-Struct. 2009;515(1-2):19-25.

18. Gupta N, Nagorny R. Tensile properties of glass microballoon-epoxy resin syntactic foams. J Appl Polym Sci. 2006;102(2):1254-61.

19. Bharath Kumar BR, Zeltmann SE, Doddamani M, Gupta N, Uzma, Gurupadu S, et al. Effect of cenosphere surface treatment and blending method on the tensile properties of thermoplastic matrix syntactic foams. J Appl Polym Sci 2016;133. http://dx.doi.org/10.1002/app.43881.

20. Mohsen, 2017. "The rise of 3-D printing: The advantages of additive manufacturing over traditional manufacturing," Business Horizons, Elsevier, vol. 60(5), pages 677-688.

21. D. Goh, V. Dikshit, A.P. Nagalingam, G.L. Goh, S. Agarwala, S.L. Sing, J. Wei, and W.Y. Yeong, Mater. Des. 137, 79 (2018).

22. Singh, A.K., B. Saltonstall, B. Patil, N. Hoffmann, M. Doddamani, and N. Gupta. 2018. Additive Manufacturing of Syntactic Foams: Part 2: Specimen Printing and Mechanical Property Characterization. JOM, 70(3): 310-314.

23. Wang Z, Gao D. 2014, Friction and wear properties of stainless-steel sliding against polyetheretherketone and carbon-fiber-reinforced polyetheretherketone under natural seawater lubrication. Design53, 881-887. (doi:10.1016/j.matdes.2013.07.096).

24. Li S. General unit cells for micromechanical analyses of unidirectional composites. Composites Part A: Applied Science and Manufacturing. 2001 Jun 1;32(6):815-826.

25. Escócio, V. A.; Pacheco, E. B. A. V.; da Silva, A. L. N.; Cavalcante, A. d. P.; Visconte, L. L. Y. Rheological Behavior of Renewable Polyethylene (HDPE) Composites and Sponge Gourd (Luffa cylindrica) 
Residue. Int. J. Polym. Sci. 2015, 2015, 1-

26. Mohanty, S.; Nayak, S. K. Short Bamboo Fiber-reinforced HDPE Composites: Influence of Fiber Content and Modification on Strength of the Composite. J. Reinf. Plast. Compos. 2010, 29, 2199-

27. Shaikh, H.; Anis, A.; Poulose, A. M.; Alam, M.; A-Otaibi, M. N.; Alam, M. A.; Al-Zahrani, S. M. Studies on High Density Polyethylene Reinforced with Phosphate Ore Particles: Thermal, Rheological, Mechanical and Morphological Properties. Polym.-Plast. Technol. Eng. 2016, 55, 1831-

28. Mae H, Omiya M, Kishimoto K. Effects of strain rate and density on tensile behavior of polypropylene syntactic foam with polymer microballoons. Mat Sci Eng A-Struct. 2008;477(1-2):168-78.

29. Mae H. Effects of local strain rate and micro-porous morphology on tensile mechanical properties in PP/EPR blend syntactic foams. Mat Sci Eng A-Struct. 2008;496(1-2):455-63.

30. Patel, P., Hull, T. R., McCabe, R. W., Flath, D., Grasmeder, J., and Percy, M., (2010), Mechanism of Thermal Decomposition of Poly (Ether Ether Ketone) (PEEK) From a Review of Decomposition Studies. Polymer Degradation and Stability. 95(5), pages 709-718.

31. Tsai, C. J., Perng, L. H., and Ling, Y. C., (1997), "A Study of Thermal Degradation of Poly (Aryl-EtherEther-Ketone) using Stepwise Pyrolysis/Gas Chromatography/Mass Spectrometry", Rapid Communications in Mass Spectrometry, 11, 1987-1995.

\section{Tables}

Table 1: Properties of HGMs as received from supplier

\begin{tabular}{|lllll|}
\hline & Density $\left(\mathbf{g} / \mathrm{cm}^{3}\right)$ & Particle size $(\mathrm{mm})$ & $\begin{array}{l}\text { Wall thickness } \\
(\mathbf{m m})\end{array}$ & Thermal conductivity $(\mathrm{W} / \mathrm{mK})$ \\
\hline LDHGM & 0.125 & 65 & 1.16 & 0.102 \\
\hline MDHGM & 0.231 & 57 & 0.78 & 0.211 \\
\hline HDHGM & 0.572 & 53 & 0.78 & 0.256 \\
\hline
\end{tabular}

Table 2. MFI comparison 


\begin{tabular}{|lll|}
\hline Composition & MFI (g/10 min) & Standard Deviation \\
& Mean value & \\
\hline PEEK & 5.2 & 0.4 \\
\hline LDPE10 & 3.4 & 0.3 \\
\hline LDPE15 & 2.7 & 0.2 \\
\hline LDPE20 & 1.9 & 0.2 \\
\hline MDPE10 & 3.1 & 0.2 \\
\hline MDPE15 & 2.1 & 0.1 \\
\hline MDPE20 & 1.6 & 0.1 \\
\hline HDPE10 & 2.9 & 0.2 \\
\hline HDPE15 & 1.9 & 0.1 \\
\hline HDPE20 & 1.2 & 0.1 \\
\hline
\end{tabular}

Table 3: Densities of the PEEK and PEEK/HGMs composites.

\begin{tabular}{|c|c|c|c|c|c|c|c|c|c|}
\hline & \multicolumn{3}{|c|}{$\begin{array}{l}\text { Measured Density } \\
\left(\mathrm{g} / \mathrm{cm}^{3}\right)\end{array}$} & \multicolumn{3}{|c|}{ Theoretical density $\left(\mathrm{g} / \mathrm{cm}^{3}\right)$} & \multicolumn{3}{|c|}{$\begin{array}{l}\text { Glass transition } \\
\text { Temperature }(\mathrm{Tg}) \\
\left({ }^{\circ} \mathrm{C}\right)\end{array}$} \\
\hline PEEK & $1.3 \pm 002$ & & & & & & 143 & & \\
\hline & $10 \%$ & $15 \%$ & $20 \%$ & $10 \%$ & $15 \%$ & $20 \%$ & $10 \%$ & $15 \%$ & $20 \%$ \\
\hline LDPE & $1.32 \pm 002$ & $1.34 \pm 002$ & $1.37 \pm 002$ & 1.1 & 0.9 & 0.7 & 143 & 143 & 143 \\
\hline MDPE & $1.29 \pm 002$ & $1.21 \pm 003$ & $1.17 \pm 002$ & 1.21 & 1.06 & 0.9 & 143 & 144 & 144 \\
\hline HDPE & $1.25 \pm 003$ & $1.19 \pm 001$ & $1.09 \pm 003$ & 1.29 & 1.19 & 1.11 & 147 & 148 & 148 \\
\hline
\end{tabular}

Figures 


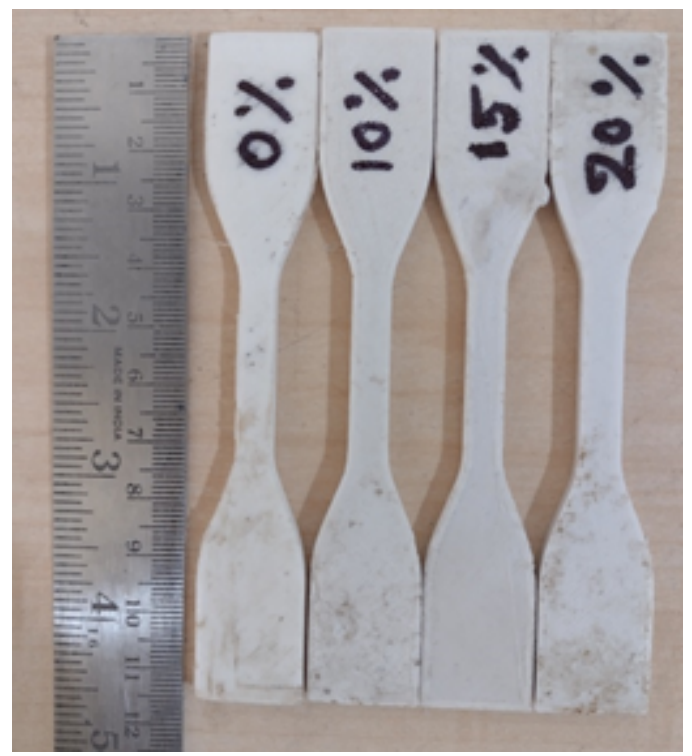

Figure 1

Tensile specimen of PEEK/HGM composite parts

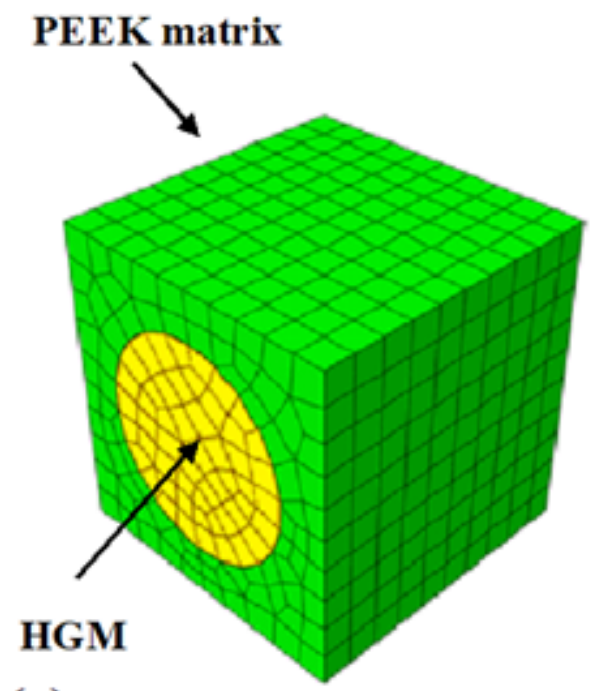

(a)

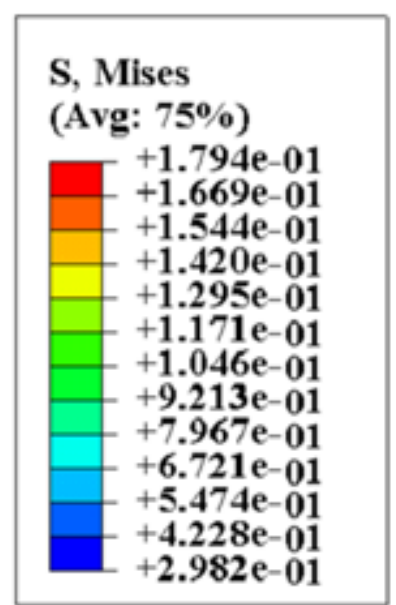

(b)

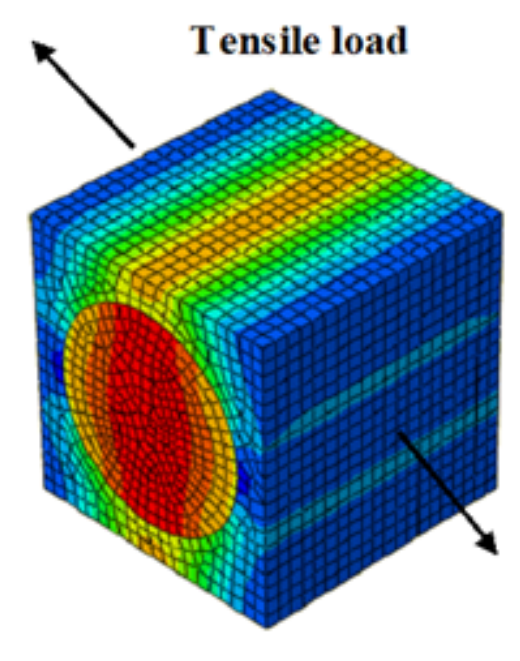

Figure 2

(a) uniform cubical meshes of a unit cell, and (b) stress distribution of hollow glass microsphere. 

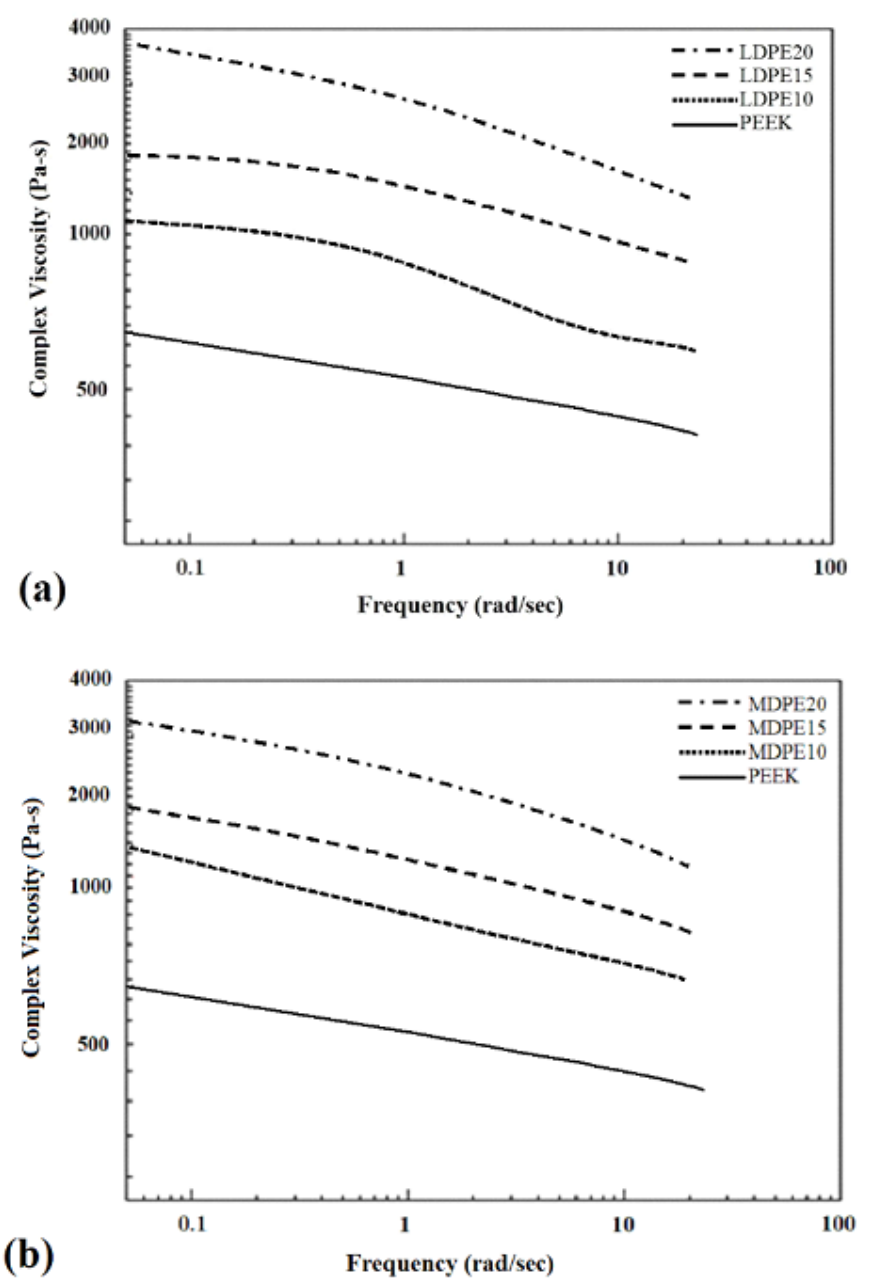

(b)

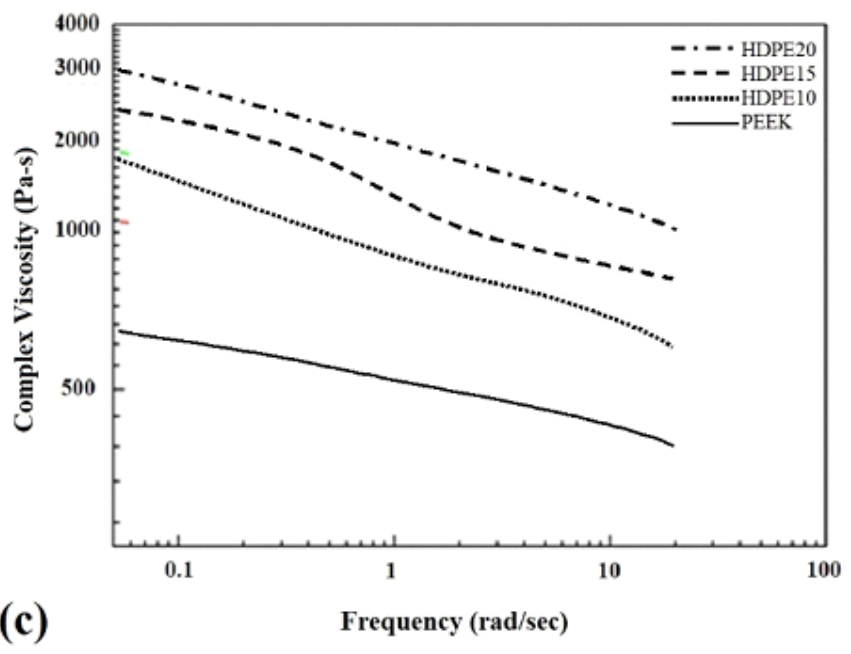

Figure 3

Complex viscosity of (a) PEEK/LDPE, (b) PEEK/MDPE, and (c) PEEK/HDPE. 

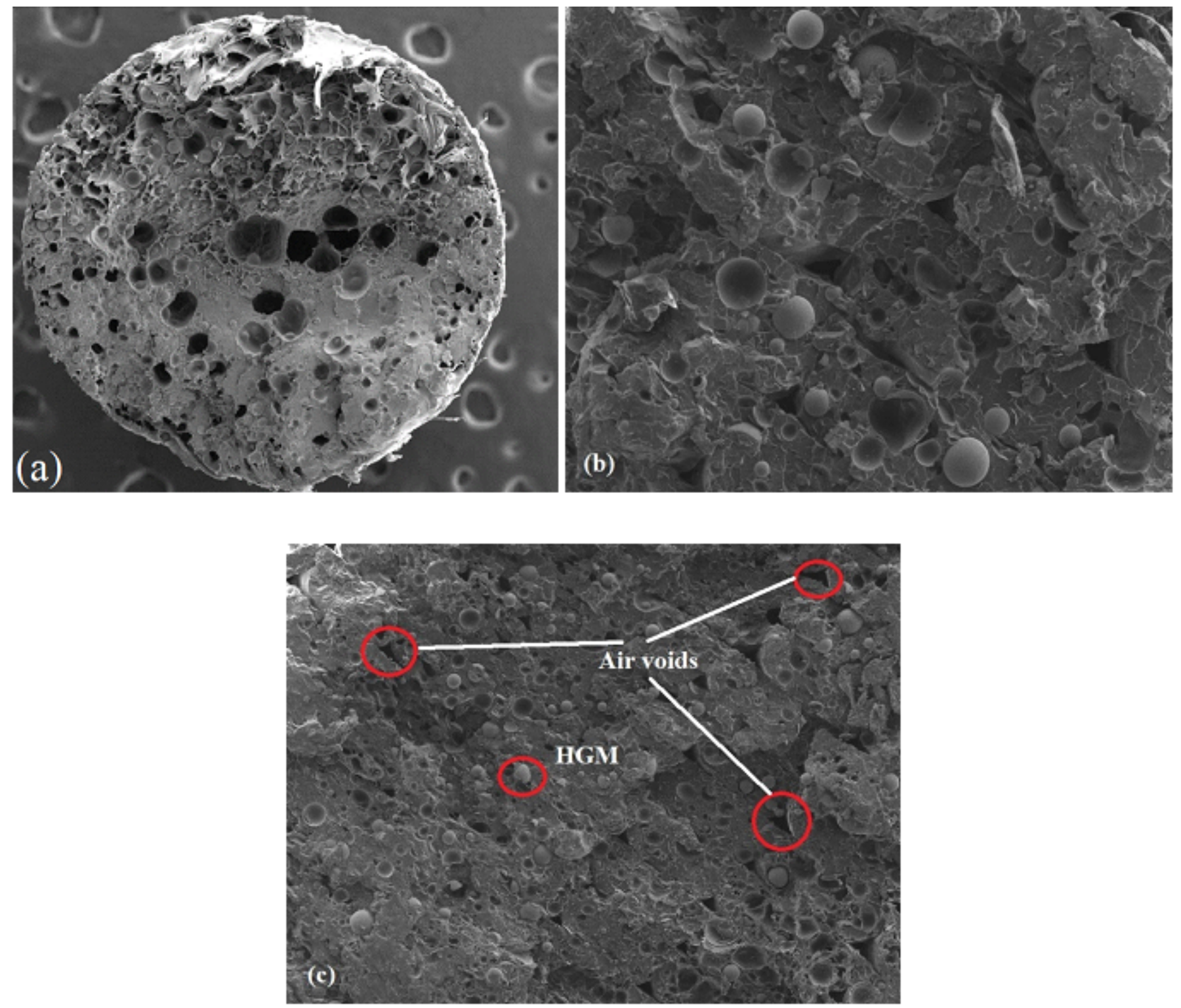

Figure 4

SEM images of MDPE composites with different concentration, (a) $10 \%$, (b) $15 \%$, and (c) $20 \%$ 


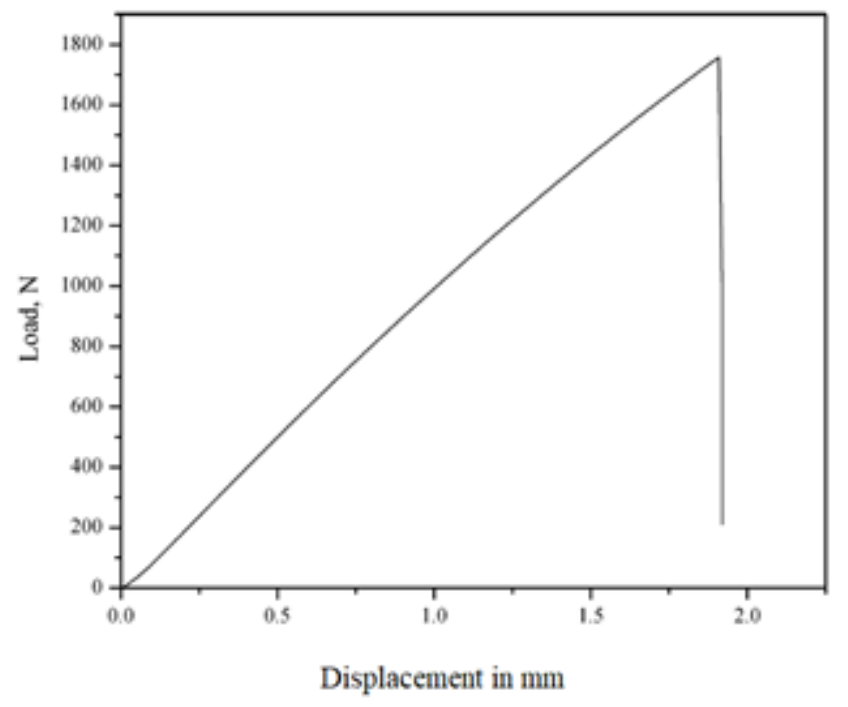

Figure 5

Load vs deflection graph of neat PEEK at loading rate of $5 \mathrm{~mm} / \mathrm{min}$.
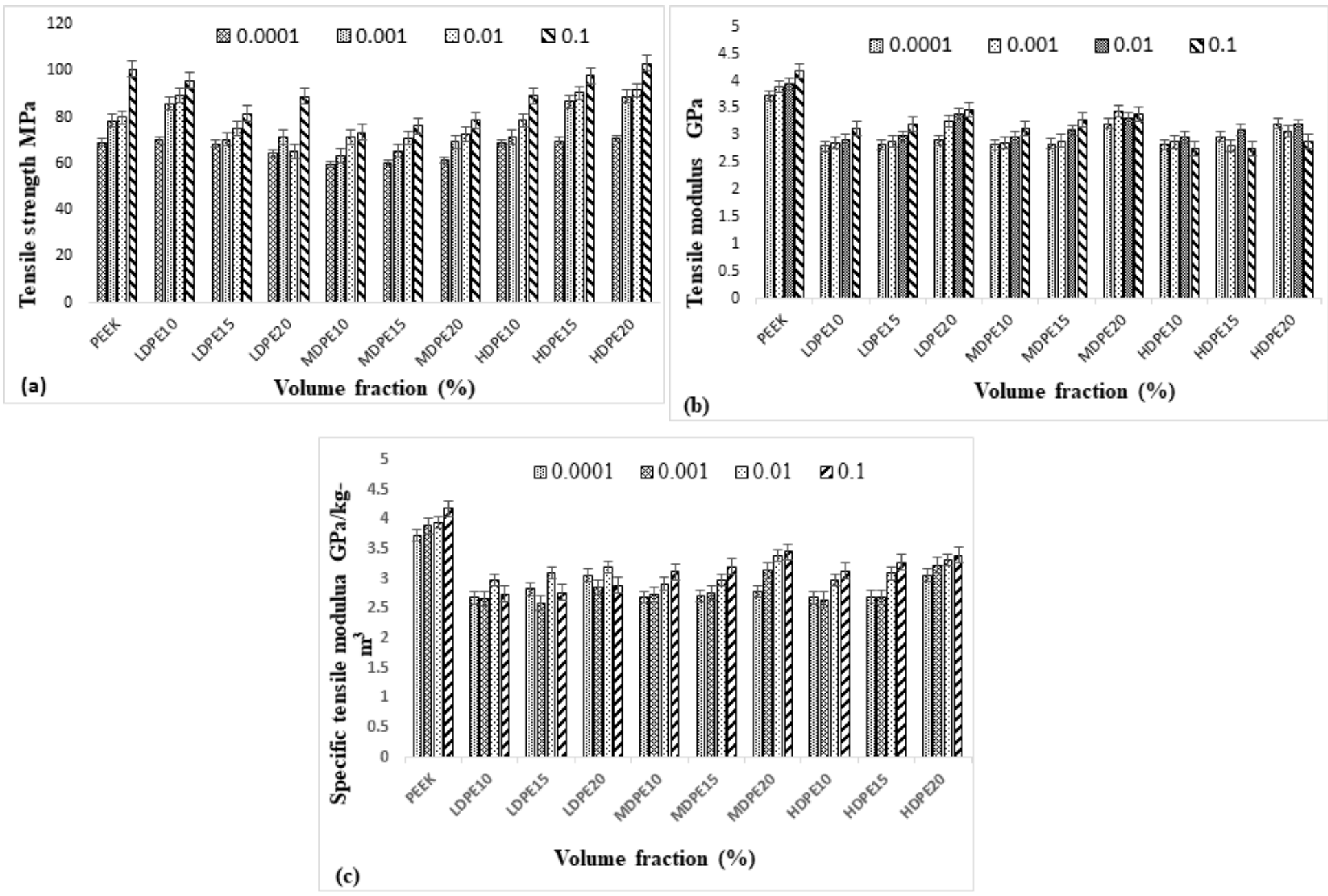
Figure 6

(a) Tensile strength and (b) tensile modulus, and (c) specific modulus of PEEK embedded with various $V_{f}$ of different density HGMs

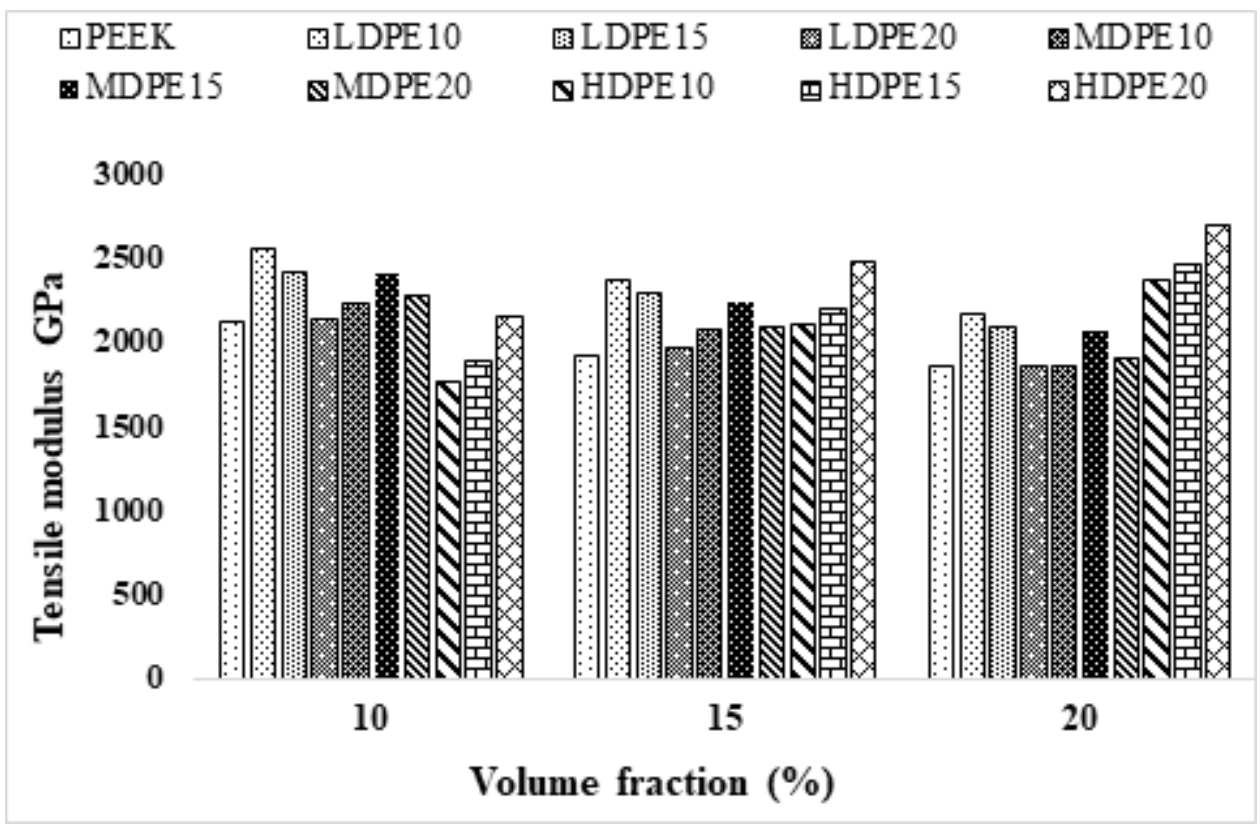

Figure 7

Quasi-static tensile modulus of simulation results at different volume fractions

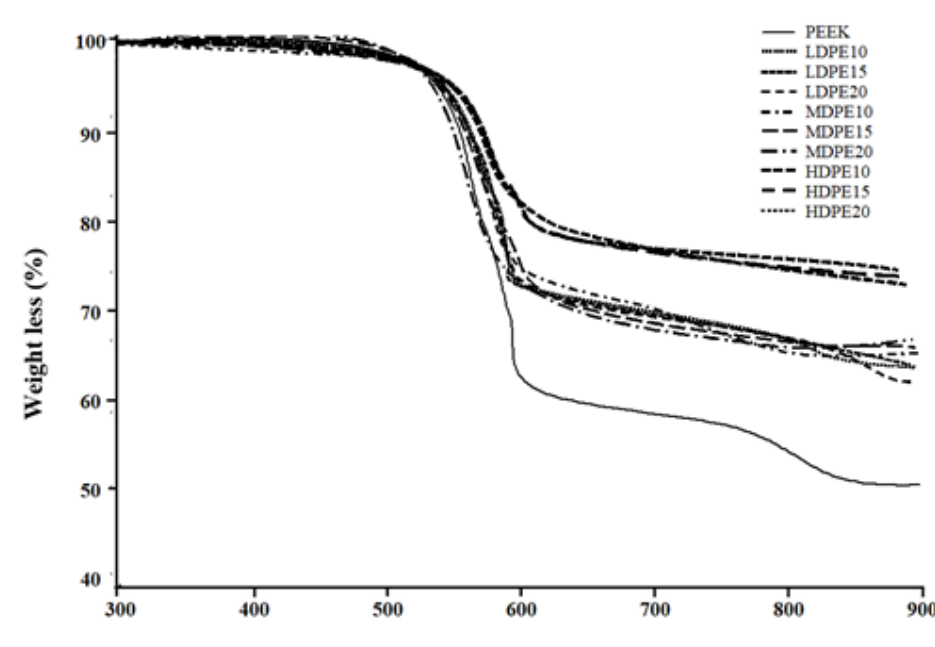

(a)

Temperature $\left({ }^{\circ} \mathrm{C}\right)$

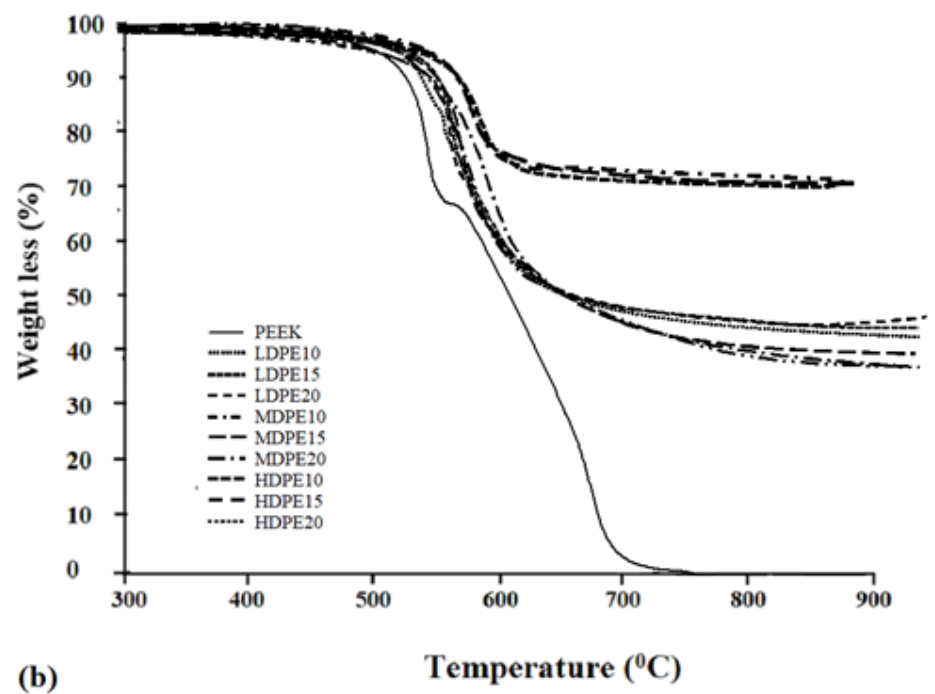

(b)

Temperature $\left({ }^{0} \mathrm{C}\right)$

Figure 8 
TGA curves for neat PEEK and PEEK/HGMs composites carried under (a) Inert environment, and (b) oxidative environment 